Check for updates

Cite this: Phys. Chem. Chem. Phys., 2019, 21, 12485

\title{
Structural and functional role of anions in electrochemical water oxidation probed by arsenate incorporation into cobalt-oxide materials $\dagger$
}

\author{
Javier Villalobos, (D) $\ddagger^{a}$ Diego González-Flores, (D) $\ddagger^{\star a b c}$ Katharina Klingan, (D) ${ }^{b}$ \\ Petko Chernev, ${ }^{\mathrm{b}}$ Paul Kubella, ${ }^{\mathrm{b}}$ Roberto Urcuyo, ${ }^{\mathrm{a}}$ Chiara Pasquini, (DD ${ }^{\mathrm{b}}$

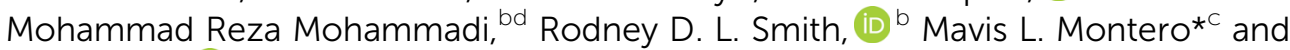 \\ Holger Dau (D) *b
}

\begin{abstract}
Direct (photo)electrochemical production of non-fossil fuels from water and $\mathrm{CO}_{2}$ requires wateroxidation catalysis at near-neutral $\mathrm{pH}$ in the presence of appropriate anions that serve as proton acceptors. We investigate the largely enigmatic structural role of anions in water oxidation for the prominent cobalt-phosphate catalyst (CoCat), an amorphous and hydrated oxide material. $\mathrm{CO}_{3}\left([(\mathrm{P} / \mathrm{As}) \mathrm{O}]_{4}\right)_{2} \cdot 8 \mathrm{H}_{2} \mathrm{O}$ served, in conjunction with phosphate-arsenate exchange, as a synthetic model system. Its structural transformation was induced by prolonged operation at catalytic potentials and probed by $\mathrm{X}$-ray absorption spectroscopy not only at the metal (Co), but for the first time also at the anion (As) $\mathrm{K}$-edge. For initially isostructural microcrystals, anion exchange determined the amorphization process and final structure. Comparison to amorphous electrodeposited Co oxide revealed that in CoCat, the arsenate binds not only at oxide-layer edges, but also arsenic substitutes cobalt positions within the layered-oxide structure in an unusual $\mathrm{AsO}_{6}$ coordination. Our results show that in water oxidation catalysis at near-neutral $\mathrm{pH}$, anion type and exchange dynamics correlate with the catalyst structure and redox properties.
\end{abstract}

Received 29th March 2019, Accepted 10th May 2019

DOI: $10.1039 / c 9 c p 01754 b$

rsc.li/pccp

\section{Introduction}

Water splitting as a source of electrons and protons for the formation of renewable fuels could become crucial in largescale sustainable storage of renewable energy. ${ }^{1,2}$ To become economically viable, catalysts must meet certain criteria including energetic efficiency and high stability under operation conditions. $^{3,4}$ Water oxidation coupled to proton reduction (resulting in $\mathrm{H}_{2}$ formation) typically is pursued efficiently either in the alkaline $(\mathrm{pH}>13)$ or acidic $(\mathrm{pH}<1)$ regime. Anions aside from hydroxide may be beneficial, but are inessential. ${ }^{5}$

\footnotetext{
${ }^{a}$ Centro de Electroquimica y Energía Química (CELEQ) and Escuela de Quimica, Universidad de Costa Rica, 11501 2060, San José, Costa Rica.

E-mail: diegoandres.gonzalez@ucr.ac.cr

${ }^{b}$ Department of Physics, Freie Universität Berlin, Arnimallee 14, 14195 Berlin, Germany.E-mail: holger.dau@fu-berlin.de

${ }^{c}$ Centro de Investigación en Ciencia e Ingeniería de Materiales (CICIMA) and Escuela de Quimica, Universidad de Costa Rica, 11501 2060, San José, Costa Rica. E-mail:mavis.montero@ucr.ac.cr

${ }^{d}$ Department of Physics, University of Sistan and Baluchestan, Zahedan, 98167-45845, Iran

$\dagger$ Electronic supplementary information (ESI) available. See DOI: 10.1039/c9cp01754b

$\$ \mathrm{~J}$. V. and D. G. F. contributed equally to this work
}

For energy-storage in the form of carbon-based fuels, the direct coupling of anodic water oxidation and cathodic $\mathrm{CO}_{2}$ reduction is of high interest, which requires water oxidation catalysts that can work efficiently close to neutral $\mathrm{pH}$ (because $\mathrm{CO}_{2}$-enrichment of the electrolyte almost inevitably results in a solution $\mathrm{pH}$ close to 7). ${ }^{6,7}$ However for efficient water oxidation in the near-neutral $\mathrm{pH}$ regime, anions in the electrolyte that can accept protons at the operational $\mathrm{pH}$ of the catalyst system are an essential requirement. ${ }^{8}$

For investigation of water oxidation at near-neutral $\mathrm{pH}$, the most frequently used electrolyte anions are phosphate ions in various protonation states (use of, e.g., $0.1 \mathrm{M}$ phosphate pH-buffer). In 2008, Kanaan and Nocera described an electrodeposited Co-phosphate electrode film that facilitates water oxidation at neutral $\mathrm{pH}$ in a phosphate-buffer electrolyte. ${ }^{9}$ They found that the phosphate anion is incorporated into the Co-based catalyst film, which therefore has been denoted as the Co-phosphate catalyst. Investigation of the amorphous catalyst film by X-ray absorption spectroscopy revealed edge-sharing $\mathrm{CoO}_{6}$ octahedra that form a layered-oxide structure with comparably small layer fragments. $^{10,11}$ The structural role of the phosphate anion within the catalyst film has been investigated, ${ }^{12,13}$ but nonetheless is clearly insufficiently understood. 
In general, only little is known about the functional role of anions in the catalysis. Anions are certainly a part of the catalyst structure, ${ }^{5,14-16}$ but how they contribute to the catalytic activity has been controversially debated. ${ }^{10-12,17,18}$ While it is well established that electrolyte anions serving as proton acceptors are essential for catalytic activity, ${ }^{19}$ the exact location and binding mode of the anions within the catalyst material have not been identified unambiguously. However, direct experimental observations in the typically non-crystalline catalyst materials by $\mathrm{X}$-ray absorption spectroscopy is, for the prominent phosphate anions, seriously hampered by the relevant X-ray energy range (about 2.0-2.6 keV) that is experimentally not well accessible. Consequently, XAS and X-ray pair distribution function analysis experiments performed on films deposited in phosphate or borate buffers could not give direct proof of the specific binding modes of the anions to the layer. ${ }^{13,20}$

Indirect evidence has been provided, e.g., by XRD analysis of layered oxy(hydroxides) suggesting the presence and exchange of anions in the interlayer space. ${ }^{21,22}$ Mass spectrometry and anion exchange experiments by Ullman et al. ${ }^{23}$ support that the active site in cobalt oxides involves two cobalt atoms at the layer margins, and that borate or phosphate anions can bind to the active site and inhibit the water oxidation reaction. Aiso et al. ${ }^{24}$ studied cobalt oxy(hydroxide) nanoparticles in carbonate buffer, finding that carbonate is able to act as a co-factor in water oxidation catalysis. An important catalytic role of bound nitrite ions in Ni-Fe oxide catalysts has been identified in the XPS and DFT study of Hunter et al. ${ }^{5}$ Kim et $a .^{25}$ studied different minerals containing cobalt and phosphate, where phosphate anions modulated the cobalt-oxygen coordination from $\mathrm{CoO}_{4}$ to $\mathrm{CoO}_{6}$. Structures with four-coordinated cobalt $\mathrm{CoO}_{4}$ showed higher catalytic activity and stability than five and six-coordinated cobalt. The higher catalytic activity was attributed to especially favourable water binding in materials with tetrahedral geometry and pyrophosphate groups $\left(\mathrm{P}_{2} \mathrm{O}_{7}{ }^{4-}\right)$. These studies suggest an important catalytic role of anions in water oxidation catalysts, as can be expected by considering that for the natural counterpart, the oxygen-evolving complex of photosystem II, anionic co-factors, e.g. a chloride ion and carboxylate groups, are known to play a key role in the catalytic activity. ${ }^{26,27}$

Here, we provide direct structural information on the bonding and coordination modes of electrolyte anions in the prominent cobalt-phosphate catalyst (CoCat), an amorphous and hydrated oxide material. $\mathrm{Co}_{3}\left([(\mathrm{P} / \mathrm{As}) \mathrm{O}]_{4}\right)_{2} \cdot 8 \mathrm{H}_{2} \mathrm{O}$ served, in conjunction with phosphate-arsenate exchange, as a synthetic model system. As a model anion, arsenate is advantageous because of similar acidbase properties when compared to phosphate $\left(\mathrm{pK}_{\mathrm{a} 2}\left(\mathrm{AsO}_{4}{ }^{3-}\right)\right.$ of 6.94, $\mathrm{p} K_{\mathrm{a} 2}\left(\mathrm{PO}_{4}{ }^{3-}\right)$ of 7.21), which has been extensively studied due to the biological importance of phosphate ions and arsenate toxicity. At the same time, arsenic is well suited to investigate its coordination environment by X-ray absorption fine-structure spectroscopy. These advantages enable the characterization of the structural role of the arsenate anion in cobalt-based catalysts. Eventually we identify two distinct bonding motifs, specifically the coordination of arsenate to the periphery of the cobalt oxide lattice and substitution of cobalt by arsenic at sites within the lattice.

\section{Experimental}

\section{Materials}

$\mathrm{Na}_{2} \mathrm{HPO}_{4} \geq 98 \%, \mathrm{NaH}_{2} \mathrm{PO}_{4}>99.5 \%, \mathrm{CoSO}_{4} \geq 99.5 \%$, $\mathrm{Co}\left(\mathrm{NO}_{3}\right)_{2} \cdot 6 \mathrm{H}_{2} \mathrm{O} 99 \%, \mathrm{Na}_{2} \mathrm{HAsO}_{4} \cdot 7 \mathrm{H}_{2} \mathrm{O} \geq 98,5 \%, \mathrm{CaCl}_{2} \cdot 2 \mathrm{H}_{2} \mathrm{O}$ $\geq 98 \%$, NaOH, MilliQ water, FTO glass Pilkinton NSG TEC T15, and NAFION ${ }^{\mathrm{TM}} 117$ were used. All reactants were supplied by Sigma-Aldrich and used as received, without any further purification.

\section{Synthesis}

Pakhomovskyite was synthetized by adding $20 \mathrm{~mL} 0.85 \mathrm{M}$ $\mathrm{Na}_{2} \mathrm{HPO}_{4}$ solution to $10 \mathrm{~mL}$ of $2.80 \mathrm{M} \mathrm{Co}\left(\mathrm{NO}_{3}\right)_{2} \cdot 6 \mathrm{H}_{2} \mathrm{O}$ solution (both prepared in deionized water). The resulting violet solid was washed five times with deionized water and dried at room temperature using $\mathrm{CaCl}_{2}$ as a desiccant.

Erythrite was synthetized by heating $800 \mathrm{~mL}$ of $5 \mathrm{mM} \mathrm{CoSO}_{4}$ solution to $65{ }^{\circ} \mathrm{C}$. After that, $400 \mathrm{~mL}$ of a $7 \mathrm{mM} \mathrm{Na}_{2} \mathrm{HAsO}_{4} \cdot 7 \mathrm{H}_{2} \mathrm{O}$ solution was added dropwise. The reddish solution turns pink and a precipitate is formed. The suspension was stirred and heated (at $65{ }^{\circ} \mathrm{C}$ ) for $72 \mathrm{~h}$. The obtained solid was washed five times with deionized water and dried at room temperature using $\mathrm{CaCl}_{2}$ as a desiccant.

CoCat(P) films were electrodeposited on a FTO coated glass using $100 \mathrm{~mL}$ of a $50 \mathrm{mM} \mathrm{Co}\left(\mathrm{NO}_{3}\right)_{2} \cdot 6 \mathrm{H}_{2} \mathrm{O}$ solution prepared in a $0.1 \mathrm{M}$ and $\mathrm{pH} 7$ sodium phosphate buffer. For the electrodeposition, a potential of $1.46 \mathrm{~V}$ versus RHE was applied until a of charge of $10 \mathrm{mC}$ was deposited.

CoCat(As) films were prepared in a similar way to $\operatorname{CoCat}(\mathbf{P})$. The electrolyte for deposition was a $0.1 \mathrm{M}$ and $\mathrm{pH} 7$ sodium arsenate buffer. All other parameters remained the same.

Electrochemical measurements. The catalytic activity of erythrite, pakhomovskyite and the cobalt oxides were tested in $0.1 \mathrm{M}$ phosphate or arsenate buffer $(\mathrm{pH}$ 7.0) solution using a single-compartment three-electrode electrochemical cell. CoCat(P) and CoCat(As) were prepared as described above. Erythrite and pakhomovskyite were first dispersed $(0.2 \mathrm{mg})$ in $45 \mu \mathrm{L}$ of isopropanol under sonication for $2 \mathrm{~h}$. Then, this solution was slowly drop-coated on the FTO surface. Subsequently, two drops of $0.25 \mathrm{wt} \%$ Nafion were drop-coated onto the surface to ensure the mechanical stability of the electrodes. A high-surface Pt mesh was used as a counter electrode and a $\mathrm{Ag} / \mathrm{AgCl}$ (saturated) as a reference electrode. The electrochemical experiments were performed at room temperature using a potentiostat (SP-300, BioLogic Science Instruments) controlled by the EC-Lab v11.01 software package. The typical electrolyte resistance (incl. the electrode) was about $30 \Omega$; iR compensation at $85 \%$ was applied. The solution remained unstirred during the experiments. All potentials are indicated with respect to the reversible hydrogen electrode (RHE).

XAS sample preparation. After the electrochemical conditioning, electrodes were submerged for 5 minutes in MilliQ water and dried at room temperature. Consequently the samples were placed in a holder as described before ${ }^{28}$ and frozen in liquid nitrogen prior to the measurement. All samples were frozen at their resting state and with no potential applied. 
XAS measurements and simulations. X-ray absorption spectroscopy at the K-edge of cobalt and arsenic was performed at the KMC-3 beamline at the BESSY synchrotron (HelmholtzZentrum Berlin, Germany) at $20 \mathrm{~K}$ in a liquid-helium cryostat as described elsewhere. ${ }^{29}$ Spectra were recorded in the fluorescence mode using a 13-element Ge detector (Canberra). The extracted spectrum was weighted by $k^{3}$ and simulated in $k$-space $\left(E_{0}=\right.$ $7710 \mathrm{eV}$ for cobalt and $11687 \mathrm{eV}$ for arsenic). $\mathrm{Na}_{2} \mathrm{HAsO}_{4} \cdot 7 \mathrm{H}_{2} \mathrm{O}$ powder (reagent grade $>98 \%$, Sigma Aldrich) was used for energy calibration at the arsenic edge. All EXAFS simulations were performed using in-house software (SimX3) after calculation of the phase functions with the FEFF program (version 8.4, selfconsistent field option activated). Atomic coordinates of the FEFF input files were generated from several reasonable structural models (ref. 30 for pakhomovskyite and ref. 31 for erythrite); the EXAFS phase functions did not depend strongly on the details of the used model. An amplitude reduction factor $\left(S_{0}{ }^{2}\right)$ of 0.85 was used for cobalt and 0.9 for arsenic. The data range used in the simulation was $34.3-548.7 \mathrm{eV}\left(3-12 \AA^{-1}\right)$. A cosine window covering $10 \%$ on the left side and $10 \%$ on the right side of the EXAFS spectra was used to suppress the side lobes in all the Fourier transforms. The EXAFS simulations were optimized by the minimization of the error sum obtained by summation of the squared deviations between measured and simulated values (leastsquares fit). The fit was performed using the Levenberg-Marquardt method with numerical derivatives. The provided error ranges of the fit indicate the $68 \%$ confidence intervals of the corresponding fit parameter. The fit error was calculated as described in ref. 32 . The number of independent data points resulting from the $k$ - and $R$-ranges used for the data fitting was 29 .

\section{Results}

Vivianite minerals can comprise different types of transition metals such as Co, Fe, and Ni; and two different anions: phosphate and arsenate. In this study, we focused on the minerals pakhomovskyite (Pak: $\left.\mathrm{Co}_{3}\left(\mathrm{PO}_{4}\right)_{2} \cdot 8 \mathrm{H}_{2} \mathrm{O}\right)$ and erythrite $\left(\right.$ Ery: $\left.\mathrm{Co}_{3}\left(\mathrm{AsO}_{4}\right)_{2} \cdot 8 \mathrm{H}_{2} \mathrm{O}\right)$. These minerals are cobalt-based isostructural variants that only differ in the anion; phosphate or arsenate, respectively (Fig. 1). In the ESI $\dagger$ detailed information on the synthesis, physical and chemical characterization for both crystalline compounds is provided. The results of XRD, ATR-FTIR, SEM and EXAFS analysis are shown in Fig. S1-S9 and Tables S1-S4 (ESI $\dagger$ ).

The presence of phosphate (Pak) or arsenate (Ery) results in different bond lengths (Fig. 1): the As-O (1.70 $\AA$ - Ery) distance is slightly longer than the $\mathrm{P}-\mathrm{O}(1.55 \AA$ - Pak) distance. Vivianite minerals typically have two possible positions for metal atoms: $\mathrm{Co}(1)$ on the hexa-coordinated position (four water molecules and two oxygen atoms from the anion) and $\operatorname{Co}(2)$ on the cobalt
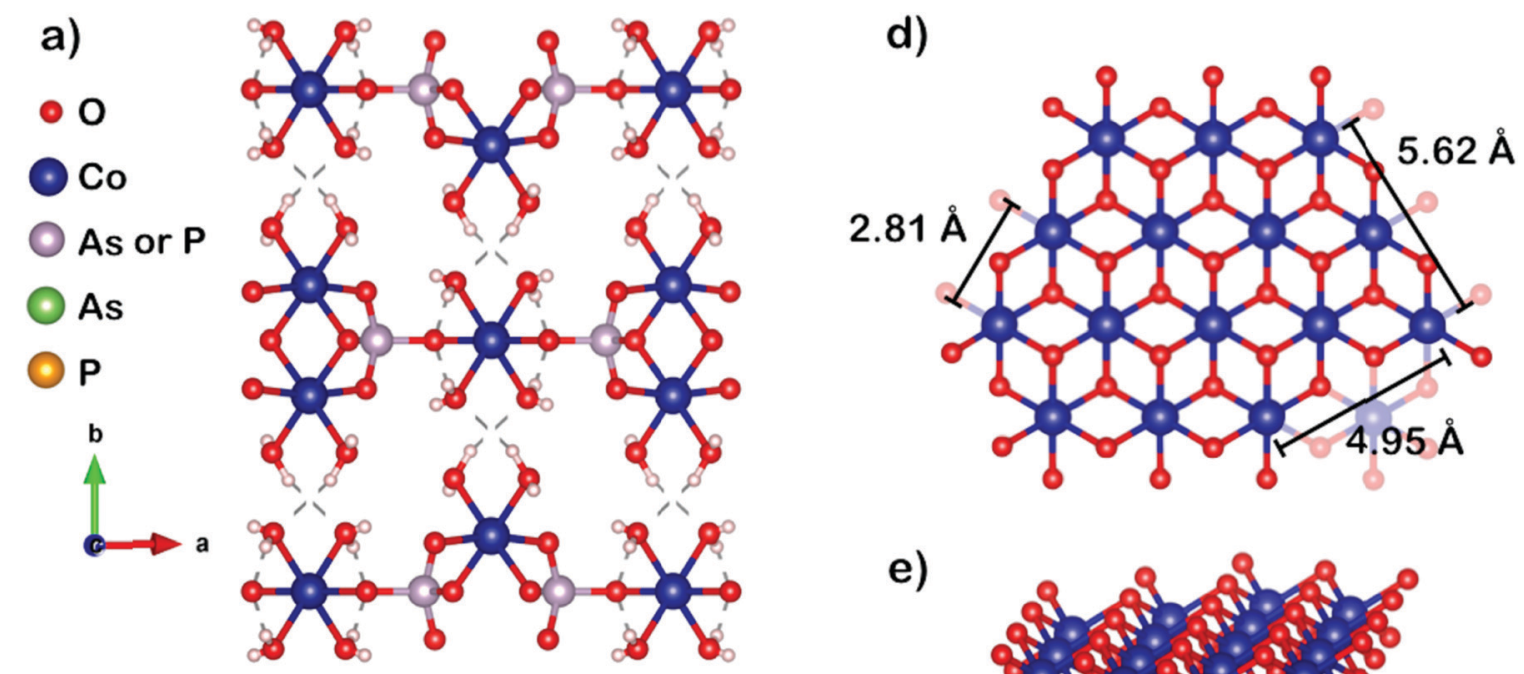

e)

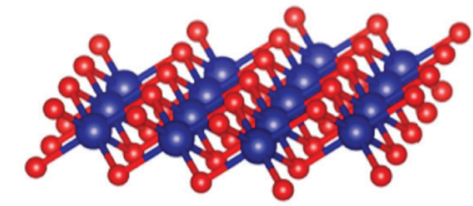

b)

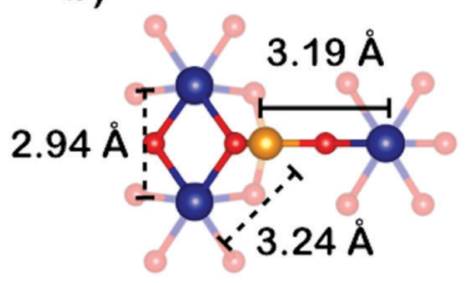

c)

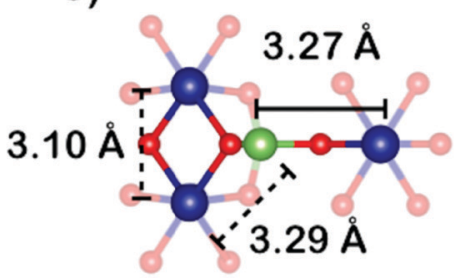

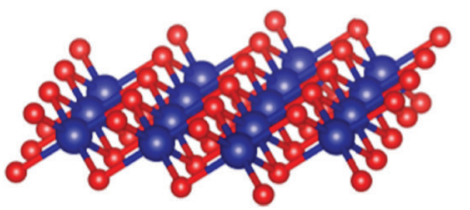

Fig. 1 (a) Typical layered structure of vivianite minerals with chemical formula $\mathrm{Y}_{3}\left(\mathrm{ZO}_{4}\right)_{2} \cdot 8 \mathrm{H}_{2} \mathrm{O}$, where $\mathrm{Y}$ is a metal or a mixture of metals with oxidation state $2+$, and $\mathrm{Z}$ is phosphorus or arsenic. The layers are connected by hydrogen bonds. (b) Phosphate binding in pakhomovskyite $\left(\mathrm{CO}_{3}\left(\mathrm{PO}_{4}\right)_{2} \cdot 8 \mathrm{H}_{2} \mathrm{O}\right)$, with the $\mathrm{Co}-\mathrm{Co}$ and $\mathrm{P}-\mathrm{Co}$ bond distances indicated. (c) Arsenate binding in erythrite $\left(\mathrm{CO}_{3}\left(\mathrm{AsO}_{4}\right)_{2} \cdot 8 \mathrm{H}_{2} \mathrm{O}\right), \mathrm{Co}-\mathrm{Co}$ and As-Co bond distances is illustrated. (d) Cobalt-oxo fragment of the CoCat, after vivianite amorphization or direct electrodeposition. (e) Layered structure of the CoCat. 
atoms bound via a di- $\mu$-oxo(anion) bridge. ${ }^{33}$ The type of anion affects the $\mathrm{Co}(2)-\mathrm{Co}(2)$ distance (Fig. 1), with Ery having a $\sim 0.2 \AA$ longer distance than Pak. The $\mathrm{Co}(1)-\mathrm{Z}$ distance to the respective phosphorous or arsenic atom is likewise affected: $3.2 \AA$ in Pak and $3.3 \AA$ in Ery.

We have previously studied the catalytic activity and amorphization of crystalline minerals from the vivianite family. ${ }^{34}$ For the present study we used an optimized amorphization protocol for Pak, which consisted of 200 cyclic voltammetry (CV) cycles at $100 \mathrm{mV} \mathrm{s}^{-1}$ in $0.1 \mathrm{M}$ phosphate buffer at $\mathrm{pH} \mathrm{7.} \mathrm{Structural}$ characterization of Pak and Ery and their amorphization are described in the ESI $\dagger$ (Fig. S10-S17, and Tables S5-S8). In the following, we focus on details of the anionic exchange in Pak as the amorphization takes place. We prepared two types of samples, namely (1) Pak-PO $\mathbf{P}_{\mathbf{4}}$-AsO $\mathbf{A}_{\mathbf{4}}$, the Pak sample is amorphized in phosphate buffer, and once the catalyst is amorphous, phosphate anions are exchanged for arsenate anions by performing $200 \mathrm{CV}$ cycles in arsenate buffer (Fig. S18, ESI $\dagger$ ), and (2) Pak-AsO $\mathbf{O}_{\mathbf{4}}-\mathbf{P O}_{\mathbf{4}}$, in which case Pak is first amorphized in arsenate buffer and then subjected to anionic exchange in phosphate buffer for $200 \mathrm{CV}$ cycles (Fig. S19, ESI $\dagger$ ). The structural analysis results from the corresponding EXAFS data at the Co and As K-edge are summarized in Fig. 2 and Tables 1 and 2.

The incorporation of arsenic in sample $\mathbf{P a k}-\mathbf{P O}_{\mathbf{4}}-\mathbf{A s O}_{4}$ (Fig. 2b) shows that once Pak is amorphized in phosphate buffer and the electrolyte is substituted by arsenate, anionic exchange can occur. The emission spectra shown in Fig. $2 \mathrm{~b}$ and $\mathrm{d}$ reveal a $\mathrm{As} / \mathrm{Co}$ mass ratio of 0.04 for $\mathbf{P a k}-\mathbf{P O}_{4}-\mathrm{AsO}_{4}$ and 0.22 for Pak-AsO $\mathbf{4}^{-}$ $\mathbf{P O}_{4}$. This result shows that (i) a higher proportion of arsenate can be incorporated in the sample if arsenate is present during amorphization, and (ii) this arsenate content is not easily exchanged (over the course of $2 \mathrm{~h}$ or $200 \mathrm{CV}$ cycles in phosphate buffer).

Based on the successful anionic exchange with arsenate anions, we extended it to the classical protocol of electrodeposition of amorphous Co oxide (CoCat) (Fig. 2e and f).${ }^{10}$ CoCat was prepared using arsenate buffer (CoCat(As)) as the initial electrodeposition electrolyte instead of the classically used phosphate buffer solution (CoCat(P)). We noticed that in general the deposition of CoCat(As) took around 10 times longer than for $\operatorname{CoCat}(\mathbf{P})$. The slower deposition rate could be related to the lower solubility of cobalt in the arsenate buffer, which causes some precipitation during the course of electrodeposition.

The experimental and simulated FT-EXAFS spectra at the Co K-edge of samples Pak-PO $\mathbf{P}_{4}-\mathbf{A s O}_{4}$, Pak-AsO $\mathrm{O}_{4}-\mathbf{P O}_{4}$, CoCat(As) and CoCat(P) are shown in Fig. 2 and Table 1 (fit results). All samples exhibit the typical distances of layered and hydrated amorphous Co-oxides ${ }^{10,14}$ at $1.90 \AA$ (Co-O), $2.81 \AA$ (Co-Co), and $5.63 \AA$ (Co-Co, a multi-scattering double distance of $2.81 \AA$ ). 3.1-3.2 $\AA$ (Co-Co) is usually observed in hydroxide phases and corresponds to a protonated $\mu$-oxo bridge. ${ }^{35}$ The typical structure of amorphous cobalt oxides is displayed in Fig. 1d and e.

The distance of $3.7 \AA$ reflects interlayer interactions which might come from water molecules $(\mathrm{Co}-\mathrm{O})$ or the presence of anions (such as arsenate) in the interlayer region (Co-As), as discussed previously. ${ }^{10,12,14}$ However, the coordination number is obscured by the noise and by possible multiple-scattering contributions from Co-As/Co-O triangles (see Fig. S20 for the effect of multiple scattering, ESI $\dagger$ ), thus preventing any further conclusion. The distance of $5.0 \AA$ most likely originates from scattering within a $\sqrt{ } 3 \cdot(2.81)=4.95 \AA$ in-layer Co-Co motif. Strong multiple scattering effects from three Co atoms on a straight line at $2 \cdot(2.81)=5.62 \AA$ contribute to the peak at $5.6 \AA$ reduced distance. This type of multiple scattering is included in the simulations. Other multiple scattering paths are expected to have only a limited effect on the spectra, even for a well-ordered structure (see Fig. S20, ESI $\dagger$ ); for an amorphous structure, small variations in bond angles would presumably suppress those multiple scattering events even further.

Electrodeposition in arsenate containing solution to obtain CoCat(As) leads to an amorphous structure with higher longrange order than the typical CoCat(P), which has been widely studied and described elsewhere. ${ }^{10,14}$ We would like to clarify that these materials can also be correctly described as highly disordered nanocrystals. The amorphization protocol leading to $\mathbf{P a k}-\mathbf{P O}_{4}-\mathbf{A s O}_{4}$ and $\mathbf{P a k}-\mathrm{AsO}_{\mathbf{4}}-\mathbf{P O}_{4}$ results in catalysts with higher long-range order compared with directly electrodeposited catalysts, as evidenced by the increased peak amplitudes for distances around $2.83 \AA$ and $5.65 \AA$, attributed to Co-Co (di- $\mu$-oxo bridge) and 2(Co-Co), respectively. The EXAFS data at the cobalt K-edge show very similar distances and slightly higher amplitudes for Pak- $\mathbf{A s O} \mathbf{O}_{\mathbf{4}}-\mathbf{P O}_{\mathbf{4}}$ compared with $\mathbf{P a k}-\mathbf{P O}_{\mathbf{4}}-\mathbf{A s O}_{\mathbf{4}}$. Even though both samples share the same structural motifs like Pak-PO $\mathbf{P O}_{\mathbf{4}}$ at the cobalt K-edge, drastic structural changes occur at the arsenic K-edge. In particular, the EXAFS spectrum of sample Pak-PO $\mathbf{P O}_{\mathbf{4}}-\mathbf{A s O}_{4}$ in Fig. 2b clearly reveals a main peak that corresponds to a $1.69 \AA \mathrm{As}-\mathrm{O}$ distance. The coordination number for this distance is slightly higher than 4, indicative of a coordination number expansion of the arsenic atom. ${ }^{36}$ The only other peak above the noise level corresponds to a $3.15 \AA$ distance, which can be assigned to a As-Co distance. More well-resolved FT peaks are found for Pak-AsO $_{4}-\mathbf{P O}_{4}$ (Fig. 2d and Table 2).

In Pak-AsO $\mathrm{O}_{4}-\mathrm{PO}_{4}$ an As-X distance of $3.18 \AA$ is found at the arsenic K-edge, and a Co-X at $\approx 3.1 \AA$ at the cobalt K-edge. We conclude that As-X and Co-X distances are more likely identical and correspond to a Co-As motive. Based on the fact that molecular models confirmed the presence of $\mu$-phosphate-bridges (phosphate bridging between two di- $\mu$-oxo bridged cobalt ions) ${ }^{23}$ and a similar binding mode in Pak and Ery minerals (Fig. 1), it is reasonable to assign the observed As-Co distance of 3.18 A to a $\mu$-arsenate-bridge that binds to two cobalt atoms possibly located at the edges of the layer in an analogous binding mode as the arsenate anion in Ery (Fig. 1c).

We also observed an As-Co distance of $2.83 \AA$ in $\mathbf{P a k}-\mathbf{P O}_{\mathbf{4}}$--AsO $\mathbf{S}_{4}$ and CoCat(As) which suggests that arsenic atoms can substitute some of the cobalt positions in the cobalt oxide layer. This is confirmed by the presence of long range order distances in Pak$\mathbf{P O}_{4}-\mathbf{A s O}_{4}$, like the distance of $5.66 \AA$ corresponding to 2(As-Co) di- $\mu$-oxo bridges and the $4.94 \AA$ distance corresponding to the $\sqrt{3}$ (As-Co) di- $\mu$-oxo bridges.

If arsenic indeed substitutes cobalt in the oxide layer structure, changes in its oxygen coordination sphere are expected as a consequence of the changed bonding geometry. Indeed, such changes are observed in the As-O distance that is split into two 

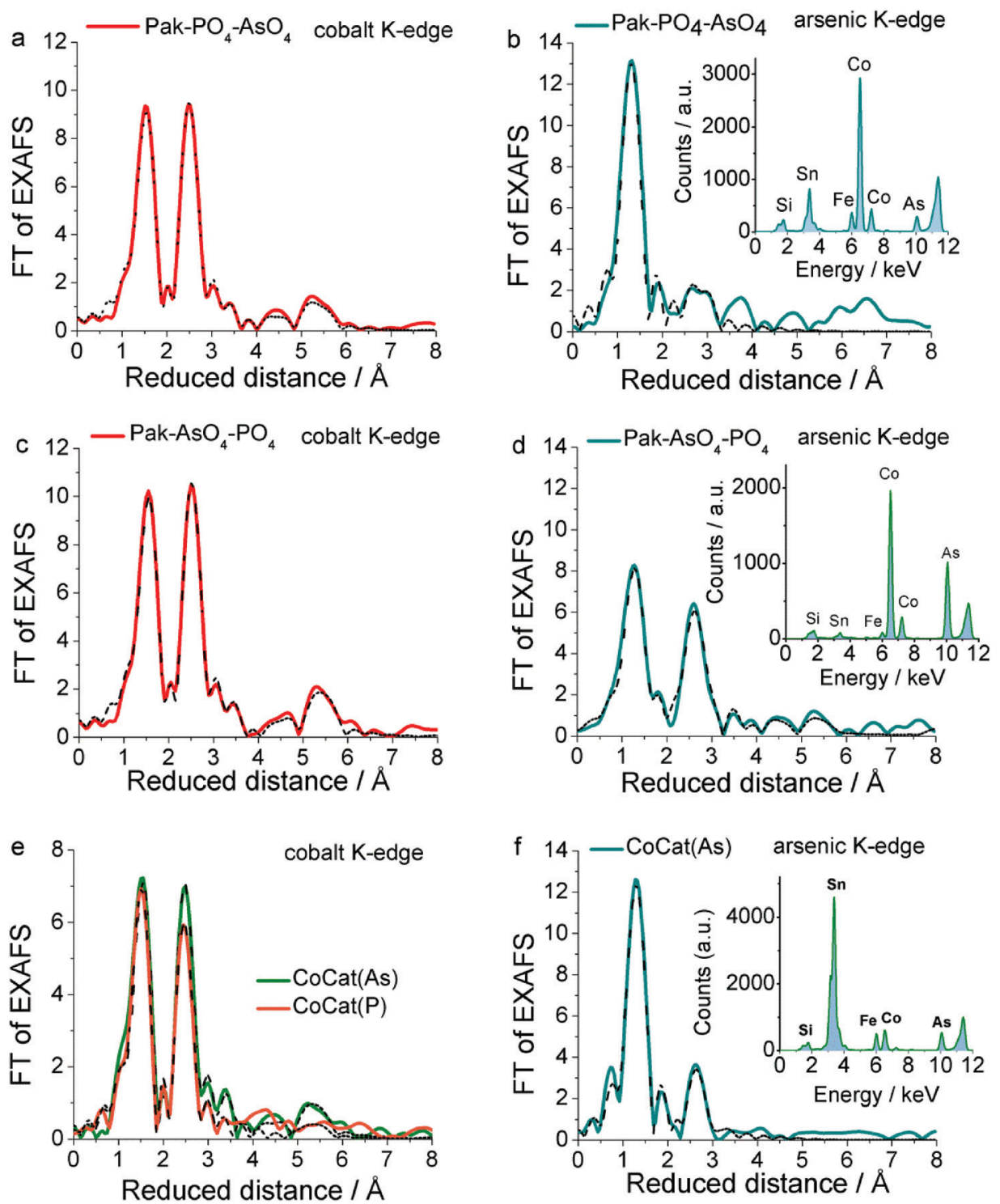

Fig. 2 Fourier-transform EXAFS spectra for pakhomovskyite after amorphization in phosphate buffer and anionic exchange in arsenate buffer $\left(\mathrm{Pak}-\mathrm{PO}_{4}\right.$-As $\left.\mathrm{O}_{4}\right)$ for: (a) cobalt K-edge and (b) arsenic K-edge; pakhomovskyite after amorphization in arsenate buffer and anionic exchange in phosphate buffer $\left(\mathrm{Pak}_{\mathbf{2}}-\mathrm{AsO}_{4}-\mathrm{PO}_{4}\right)$ for: (c) cobalt K-edge and (d) arsenic K-edge. Fourier-transform EXAFS spectra of CoCat(As) for: (e) cobalt K-edge and (f) arsenic K-edge. The electrodeposition was carried out in a solution of $\mathrm{Co}\left(\mathrm{NO}_{3}\right)_{2}$ and $0.1 \mathrm{M}$ arsenate buffer at pH 7. For the amorphization the sample was subjected to 200 cycles with $100 \mathrm{mV} \mathrm{s}{ }^{-1}$ in $0.1 \mathrm{M}$ phosphate $(\mathrm{a}$ and $\mathrm{b})$ or arsenate $(\mathrm{c}$ and $\mathrm{d})$ buffer at $\mathrm{pH} 7$ as shown in Fig. S10 (ESI $\dagger$ ). For the anionic exchange, the sample after amorphization was subjected to 200 cycles with $100 \mathrm{mV} \mathrm{s}^{-1}$ in $0.1 \mathrm{M}$ arsenate ( $a$ and b) or phosphate (c and d) buffer at pH 7 as shown in Fig. S18 and S19 (ESI†). The insets show the fluorescence emission spectra for the energy of the incoming X-ray beam of $11900 \mathrm{eV}$, the arsenic and cobalt $\mathrm{K}_{\alpha}$ peaks are indicated. The reduced distance is by about 0.3-0.4 A shorter than the precise distance obtained by EXAFS simulations. The dotted lines are results from EXAFS simulations (see Tables 1 and 2 for parameters). The strong $\mathrm{Sn}$ and Fe signals in panel $\mathrm{f}$ come from the FTO covered glass substrate.

distances of $1.66 \AA$ and $1.78 \AA$. The sum of both coordination numbers adds up to 4.7 , which is close to the coordination number observed for Pak-PO $\mathbf{P}_{4}-\mathbf{A s O}_{\mathbf{4}}$. This, in general, suggests that arsenic might be coordinating additional oxygen atoms. We also performed total reflection X-ray fluorescence (TXRF) experiments on samples exchanged for a longer time $(400$ cycles and 800 cycles equivalent to 4 and 8 hours, respectively). The arsenic concentration is found to continuously increase within Pak-PO $\mathbf{P}_{4}-\mathrm{AsO}_{4}$ and decrease within $\mathbf{P a k}-\mathrm{AsO}_{\mathbf{4}}-\mathbf{P O}_{4}$; however, a complete exchange apparently is never achieved (Fig. S21 and S22 and Tables S9 and S10, ESI $\dagger$ ).
In summary, the above results suggest that anionic exchange from phosphate to arsenate and vice versa occurs predominantly in amorphous oxide phases. Therefore it can be very slow when starting with stable crystalline materials (more than $8 \mathrm{~h}$ ); the exchange rate depends on the amorphization rate. Amorphization of the initially crystalline material results in a layered oxide similar to the CoCat material obtained by electrodeposition, but structurally more ordered. We identify two likely arsenate binding modes: (i) arsenate binds at terminal sites at the margins of oxide fragments, likely in a bidentate mode bridging between two cobalt ions and (ii) arsenic substitutes cobalt positions within 
Table 1 EXAFS absorber-backscatter distance, $R$, and coordination numbers, $N$, as determined by simulation of the $k^{3}$-weighted EXAFS spectra at the cobalt K-edge for samples Pak-AsO $\mathrm{O}_{4}-\mathrm{PO}_{4}, \mathrm{Pak}-\mathrm{PO}_{4}-\mathrm{AsO}_{4}, \mathrm{CoCat}(\mathrm{As})$ and $\mathrm{CoCat}(\mathrm{P})$

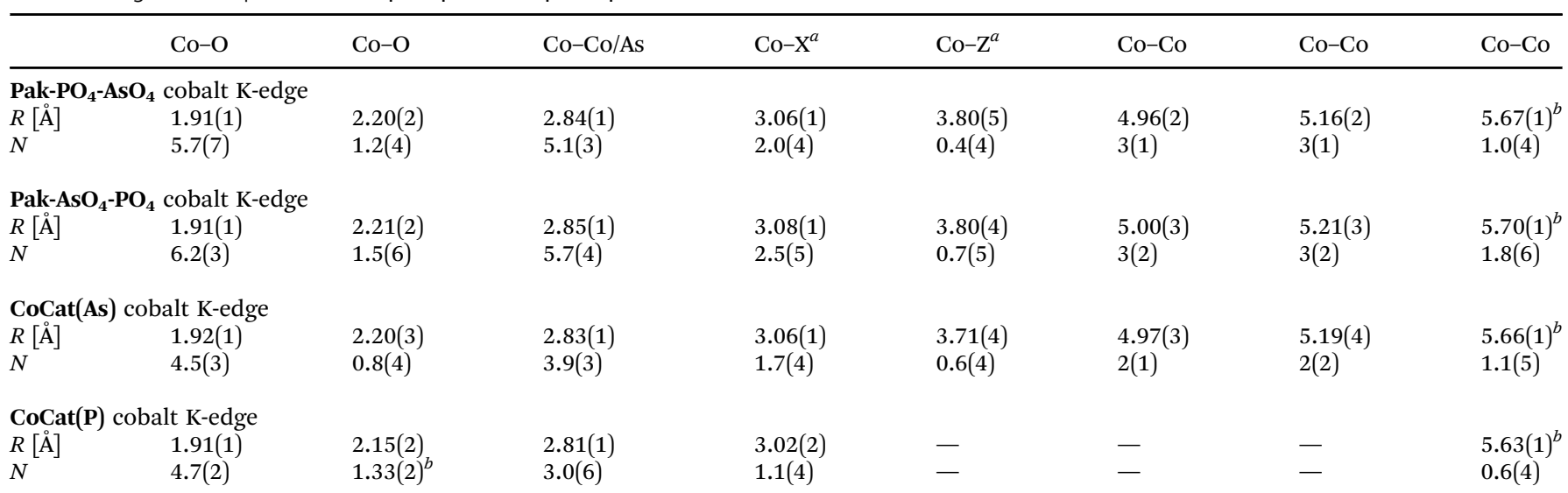

${ }^{a}$ Shells were simulated with Co-Co phase functions. ${ }^{b}$ This distance was set as twice the $2.81-2.85$ A Co-Co distance and simulated using multiplescattering simulation as described in ref. 12. The Debye-Waller factor, $\sigma$, was set to 0.071 for all simulations. The numbers in parentheses correspond to the likely error in the last digit ( $1 \sigma$ error range).

Table 2 EXAFS absorber-backscatter distance, $R$, and coordination numbers, $N$, as determined from simulation of the $k^{3}$-weighted EXAFS spectra at the arsenic $\mathrm{K}$-edge for samples $\mathrm{Pak}-\mathrm{AsO}_{4}-\mathrm{PO}_{4}, \mathrm{Pak}-\mathrm{PO}_{4}-\mathrm{AsO}_{4}$ and $\mathrm{CoCat}(\mathrm{As})$

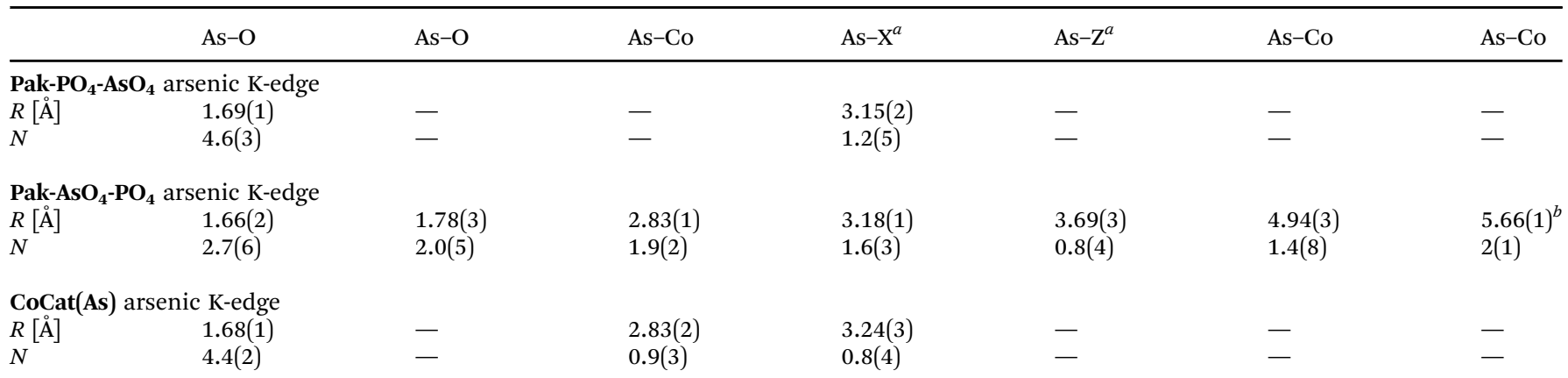

${ }^{a}$ Shells were simulated with As-Co phase functions. ${ }^{b}$ This distance was set as twice the 2.83 A As-Co distance and simulated using multiple scattering as in ref. 12. The Debye-Waller factor, $\sigma$, was set as 0.0524 for As-O distance and 0.0592 for the rest of the distances. The numbers in parentheses represent the likely error in the last digit ( $1 \sigma$ error range).

the lattice of edge-sharing $\mathrm{CoO}_{6}$ octahedra with an unusual $\mathrm{AsO}_{6}$ coordination.

\section{Redox-behavior of CoCat(As) versus CoCat(P)}

For electrochemical characterization, cyclic voltammetry was performed (Fig. S23-S25, see also Fig. S10, S11, S18 and S19, ESI $\dagger$ ) and Tafel plots were established (Fig. S26 and S27, Fig. 3 and Table S11, ESI $\dagger$ ). Fig. S25 (ESI $\dagger$ ) shows that deposition of CoCat(As) with $10 \mathrm{mC} \mathrm{cm}^{-2}$ results in a clearly lower redox area compared with the CoCat(P) film (area of the reductive redox wave in the CV). This observation is not explainable by similarly pronounced differences in the number of deposited cobalt ions because elementary analysis by ICP measurements did not reveal similarly strong differences: $120 \pm 1 \mathrm{nmol} \mathrm{cm}^{-1}$ (11.5 mC) of cobalt deposited in CoCat(P) and $91 \pm 1 \mathrm{nmol} \mathrm{cm}{ }^{-1}(8.8 \mathrm{mC})$ in CoCat(As), when the electrodeposition process is stopped after a total charge of $10 \mathrm{mC} \mathrm{cm}{ }^{-2}$ (Fig. S28, ESI $\dagger$ ).

In situ UV-vis CV experiments were performed at $420 \mathrm{~nm}$ to access possible differences of the redox-behaviour caused by the presence of arsenate (instead of phosphate) in the cobalt layer.
For $\operatorname{CoCat}(\mathbf{P})$ and $\operatorname{CoCat}(\mathbf{A s})$, a pronounced increase in the absorption of visible light is observed for increasing electrical potentials (Fig. S29 and S30, ESI $\dagger$ ). As previously shown for $\operatorname{CoCat}(\mathbf{P}),{ }^{37}$ the absorption increase is not associated with spectral changes and its magnitude traces the increased oxidation of cobalt ions quantitatively. During electrochemical in situ spectroscopy at one fixed wavelength the appropriately normalized derivative of the absorption follows closely the electrochemical current density. ${ }^{37}$ On this basis, the redox dynamics can be related to changes in the absorbance and vice versa.

In situ UV-vis spectroscopy performed in combination with electrochemical CVs reveals a first oxidative $\mathrm{Co}^{\mathrm{II}} / \mathrm{Co}^{\mathrm{III}}$ transition at $1.57 \mathrm{~V}_{\mathrm{RHE}}$ (at $1.50 \mathrm{~V}_{\mathrm{RHE}}$ in the reductive transition) and a second oxidative transition from $\mathrm{Co}^{\mathrm{III}} / \mathrm{Co}^{\mathrm{IV}}$ at $1.83 \mathrm{~V}_{\mathrm{RHE}}$ (at $1.71 \mathrm{~V}_{\mathrm{RHE}}$ in the reductive transition) for CoCat(P) (Fig. 3). These measurements are performed at $20 \mathrm{mV} \mathrm{s}^{-1}$ in $0.1 \mathrm{M}$ and $\mathrm{pH} 7$ arsenate buffer. (Additional CVs with $100 \mathrm{mV} \mathrm{s}^{-1}$ scan rate in an extended potential window are provided in Fig. S23 and S25, ESI. $\dagger$ ) The first anodic redox transition from $\mathrm{Co}^{2+}$ to $\mathrm{Co}^{3+}$ is seen to be shifted by about $100 \mathrm{mV}$ to lower potentials when arsenate is present in the catalyst 

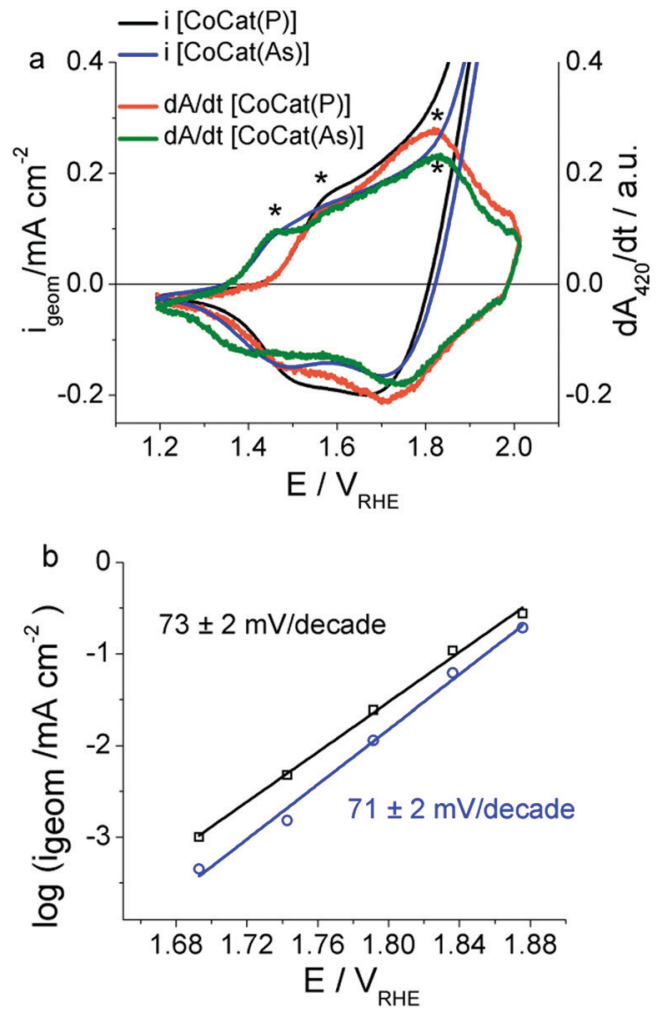

Fig. 3 (a) In situ UV-vis measurements and (b) Tafel plots of CoCat(As) and $\mathbf{C o C a t}(\mathbf{P})$. Measurements were performed in $0.1 \mathrm{M}$ and $\mathrm{pH} 7$ arsenate buffer with $20 \mathrm{mV} \mathrm{s}^{-1}$ scan rate (CVs), $40 \mathrm{~ms}$ time resolution (UV-vis). Tafel plots were collected with $50 \mathrm{mV}$ steps, each potential was applied for $4 \mathrm{~min}$. No iR compensation was applied and the ohmic resistance was $92 \Omega$. The potential was iR-corrected after the measurements. Measurements of these samples in $0.1 \mathrm{M} \mathrm{pH} 7$ phosphate buffer are available in the ESI, $\dagger$ Fig. S25. Additional spectroscopic data are provided in Fig. S29-S33 (ESI†).

film (1.47/1.41 $\mathrm{V}_{\mathrm{RHE}}$ for CoCat(As) and 1.57/1.50 $\mathrm{V}_{\mathrm{RHE}}$ for CoCat(P)). A similar cathodic shift in the cobalt redox waves due to incorporation of arsenate has also been reported for model compounds. ${ }^{38}$ By contrast, the $\mathrm{Co}^{\mathrm{III}} / \mathrm{Co}^{\mathrm{IV}}$ transition at $1.83 \mathrm{~V}_{\mathrm{RHE}}$ is not significantly affected by the presence of arsenic. A shift in the midpoint potential of $\mathrm{Co}^{\mathrm{II}} / \mathrm{Co}^{\mathrm{III}}$ transition without any shift of the $\mathrm{Co}^{\mathrm{III}} / \mathrm{Co}^{\mathrm{IV}}$ midpoint potential is also revealed by analysis of the absorption changes measured for catalyst films equilibrated for $4 \mathrm{~min}$ at the respective potential (Fig. S30, ESI $\dagger$ ).

Importantly, the incorporation of arsenic does not change the Tafel behavior (Fig. 3b), i.e., both CoCat(As) and CoCat(P) display the same Tafel slopes. Overall, the in situ UV-vis and Tafel data indicate that the incorporation of arsenate into the amorphous cobalt oxides affects only the $\mathrm{Co}^{\mathrm{II}} / \mathrm{Co}^{\mathrm{III}}$ transition, whereas the $\mathrm{Co}^{\mathrm{III}} / \mathrm{Co}^{\mathrm{IV}}$ transition remains unaffected, explaining unaltered catalytic properties. ${ }^{37,39}$

\section{Concluding discussion}

This study provides the first example where the coordination and binding modes of the anions in the amorphous catalyst material are directly addressed by analysis of EXAFS spectra. This became possible by phosphate-arsenate exchange and use of arsenate as a probe anion. The XANES spectra do not provide clear evidence for arsenic in oxidation states other than $\mathrm{As}^{\mathrm{V}}$, but qualitatively support major variations of the arsenic coordination environment when comparing the $\mathrm{AsO}_{4}{ }^{3-}$ ion and the arsenic ions within the amorphous catalyst material (Fig. S17, ESI $\dagger$ ). The EXAFS simulations suggest that the As-O distance splits into two distances of $1.66 \AA$ and $1.78 \AA$ in the amorphized but still well ordered structures of Pak-AsO $\mathbf{O}_{\mathbf{4}}-\mathbf{P O}_{\mathbf{4}}$. By comparison, in less ordered structures an average distance of $1.69 \AA$ (Pak-PO $\mathbf{P}_{\mathbf{4}}-\mathbf{A s O}_{\mathbf{4}}$ and CoCat(As)) was observed. The overall As-O coordination number turned out to be larger than four in all amorphous or amorphized materials. Such arsenic coordination can be found in nature; for example, arsenic in oxidation state five with an expanded coordination sphere of 6 forming pseudooctahedral groups is present in minerals such as $\mathrm{As}_{2} \mathrm{O}_{5},{ }^{40} \mathrm{H}_{5} \mathrm{AsO}_{13},{ }^{41}$ $\mathrm{BaH}_{6} \mathrm{As}_{4} \mathrm{O}_{14},{ }^{42} \mathrm{NaHAs}_{2} \mathrm{O}_{6},{ }^{43}$ and compounds of formula $\mathrm{M}^{\mathrm{II}} \mathrm{As}_{2} \mathrm{O}_{6}$ (where $\mathrm{M}$ can be $\mathrm{Ca}$ and $\mathrm{Pb}$, for example). ${ }^{36}$ Four-fold coordinated arsenate groups have As-O distances between 1.64 and $1.70 \AA$, and six coordinated arsenate groups between 1.80 and $1.90 \AA$. We propose that the $1.78 \AA$ distance (Table 2) indicates the expansion of the oxygen coordination sphere to six by a portion of the arsenate anions. This assertion is supported by pronounced intensity change in the main absorption edge of the amorphous catalysts $(>3)$ with respect to crystalline Ery $(\sim 2)$ (XANES in Fig. S17a, ESI $\dagger$ ). Normalized arsenic K-edge maxima higher than 3 have been observed for $\mathrm{CaAs}_{2} \mathrm{O}_{6}$ and $\mathrm{LiAsO}_{3}$, in both of which arsenic(v) is 6-fold coordinated. ${ }^{44}$

For the Co-As distances, the following scenarios of anion binding are conceivable:

(i) Arsenate binds at terminal sites at the margins of oxide fragments, likely in a bidentate mode bridging between two cobalt ions (Co-As distance of about $3.2 \AA$ ).

(ii) Arsenic substitutes for cobalt within the oxide layers (Co-As distance of about $2.8 \AA$ ). This requires an increase of the arsenic coordination number to six, in order to match the octahedral geometry of the cobalt-oxo lattice of the oxide layer. The comparatively high coordination number of the $2.83 \AA$ Co-As distance of $\sim 2$ (in Table 2) suggests that six-coordinated arsenic ions do not bind at an edge site, but within the Co-oxide structure. The slight increase in the typically very precise $\mathrm{Co}-\mathrm{Co}$ distance of 2.81(1) $\AA$ in CoCat(P) to 2.85(1) $\AA$ in Pak-AsO $\mathbf{O}_{\mathbf{4}}-\mathbf{P O}_{4}$ (Table 2 and our previous data ${ }^{37}$ ) is in line with arsenic ions binding within the Co oxide layers.

Based on the results discussed above we propose two main arsenate binding modes, (i) terminal coordination at cobalt-oxide edges and (ii) substitution of cobalt, as schematically shown in Fig. 4.

It is likely that the first binding mode applies also to phosphate ions. For the substitution of cobalt by arsenic (second binding mode), analogous phosphate binding is conceivable, but less certain because chemical differences might prevent the required expansion of the phosphate coordination sphere. ${ }^{23,44}$

In spite of similarities, phosphate and arsenate differ in their chemical properties. ${ }^{23,44-47}$ Upon arsenate-phosphate exchange, we observe a cathodic shift of the $\mathrm{Co}^{\mathrm{II}} / \mathrm{Co}^{\mathrm{III}}$ midpoint potential by about $100 \mathrm{mV}$. This shift could result directly from the presence 


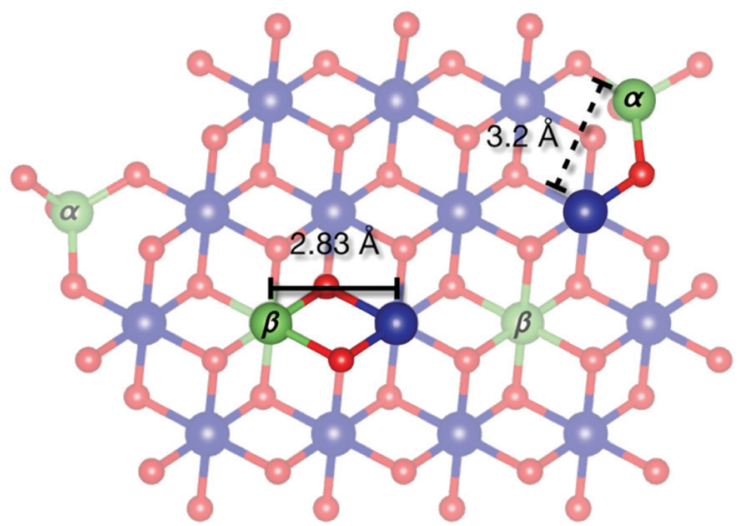

Fig. 4 Proposed structural model for CoCat deposited in arsenate buffer CoCat(As). View from above (only one cluster/layer is shown), $\alpha$ arsenate ions can bind to the margins of the layers forming $\mu$-arsenate bridges between two cobalt centers with a $3.2 \AA$ As-Co distance. Arsenic can also substitute cobalt positions ( $\beta$ arsenate) forming $\mu$-oxo bridges with Co-As distances of $2.83 \AA$. Arsenic atoms inside the cobalt oxide layer have an expansion of the coordination number, from 4 to 6 .

of arsenate ions (instead of phosphate ions), but might also relate to the increased Co oxide cluster size observed in the presence of arsenate (Fig. 2). In any event, the mechanistically more relevant $\mathrm{Co}^{\mathrm{III}} / \mathrm{Co}^{\mathrm{IV}}$ oxidation potential is essentially unaffected by the phosphate/arsenate exchange as are the corresponding electrocatalytic properties (the same Tafel slope for CoCat(P) and CoCat(As)). We conclude that the phosphate or arsenate ions do not directly participate in the rate determining step of the water oxidation reaction, aside from their role in preventing local alkalization by mediating proton transport. ${ }^{19,48}$

\section{Conflicts of interest}

There are no conflicts to declare.

\section{Acknowledgements}

This work was funded by Posgrado en Química and Vicerrectoría de Investigación (UCR), CONICIT-MICIT (Costa Rica), the German Federal Ministry of Education and Research (Bundesministerium für Bildung und Forschung; BMBF; CO2EKAT project, 03SF0523) and the Deutsche Forschungsgemeinschaft (DFG, priority program SP 1613). We thank the Helmholtz-Zentrum Berlin (HZB) for beamtime allocation and general support at the KMC-3 synchrotron beamline of the BESSY synchrotron in Berlin-Adlershof, and Dr Ivo Zizak for special support. We thank Dr Stefan Loos (Berlin), Gabriela Fernández, David Sánchez, Diego Jiménez and Emerson Zamora (all San José, Costa Rica) for data collection. R. U. thanks Marko Burghard of the Max Planck Institute for Solid State Research (Stuttgart) and for productive discussion.

\section{References}

1 J. A. Turner, Science, 2004, 305, 972-974.

2 T. R. Cook, D. K. Dogutan, S. Y. Reece, Y. Surendranath, T. S. Teets and D. G. Nocera, Chem. Rev., 2010, 110, 6474-6502.
3 H. Dau, E. Fujita and L. Sun, ChemSusChem, 2017, 1-9.

4 C. Costentin and D. G. Nocera, Proc. Natl. Acad. Sci. U. S. A., 2017, 114, 13380-13384.

5 B. M. Hunter, W. Hieringer, J. R. Winkler, H. B. Gray and A. M. Müller, Energy Environ. Sci., 2016, 9, 1734-1743.

6 C. W. Li, J. Ciston and M. W. Kanan, Nature, 2014, 508, 504-507.

7 D. G. Nocera, Acc. Chem. Res., 2017, 50, 616-619.

8 K. Klingan, T. Kottakkat, Z. P. Jovanov, S. Jiang, C. Pasquini, F. Scholten, P. Kubella, A. Bergmann, B. Roldan Cuenya, C. Roth and H. Dau, ChemSusChem, 2018, 11, 3449-3459.

9 M. W. Kanan and D. G. Nocera, Science, 2008, 321, 1072-1075.

10 M. Risch, V. Khare, I. Zaharleva, L. Gerencser, P. Chernev and H. Dau, J. Am. Chem. Soc., 2009, 131, 6936-6937.

11 M. W. Kanan, J. Yano, Y. Surendranath, M. Dincǎ, V. K. Yachandra and D. G. Nocera, J. Am. Chem. Soc., 2010, 132, 13692-13701.

12 M. Risch, K. Klingan, F. Ringleb, P. Chernev, I. Zaharieva, A. Fischer and H. Dau, ChemSusChem, 2012, 5, 542-549.

13 P. Du, O. Kokhan, K. W. Chapman, P. J. Chupas and D. M. Tiede, J. Am. Chem. Soc., 2012, 134, 11096-11099.

14 M. W. Kanan, J. Yano, Y. Surendranath, M. Dinca, V. K. Yachandra and D. G. Nocera, J. Am. Chem. Soc., 2010, 132, 13692-13701.

15 G. Kwon, H. Jang, J. S. Lee, A. Mane, D. J. Mandia, S. R. Soltau, L. M. Utschig, A. B. F. Martinson, D. M. Tiede, H. Kim and J. Kim, J. Am. Chem. Soc., 2018, 140, 10710-10720.

16 A. J. Esswein, Y. Surendranath, S. Y. Reece and D. G. Nocera, Energy Environ. Sci., 2011, 4, 499-504.

17 C. Costentin and D. G. Nocera, Proc. Natl. Acad. Sci. U. S. A., 2017, 114, 13380-13384.

18 T. P. Keane, D. K. Bediako, D. G. Nocera, C. N. Brodsky, C. Shi, C. Costentin and S. J. L. Billinge, ACS Appl. Energy Mater., 2018, 2, 3-12.

19 Y. Surendranath, M. W. Kanan and D. G. Nocera, J. Am. Chem. Soc., 2010, 132, 16501-16509.

20 C. L. Farrow, D. K. Bediako, Y. Surendranath, D. G. Nocera and S. J. L. Billinge, J. Am. Chem. Soc., 2013, 135, 6403-6406.

21 F. Song and X. Hu, Nat. Commun., 2014, 5, 1-9.

22 J. B. Gerken, J. G. McAlpin, J. Y. C. Chen, M. L. Rigsby, W. H. Casey, R. D. Britt and S. S. Stahl, J. Am. Chem. Soc., 2011, 133, 14431-14442.

23 A. M. Ullman, C. N. Brodsky, N. Li, S. L. Zheng and D. G. Nocera, J. Am. Chem. Soc., 2016, 138, 4229-4236.

24 K. Aiso, R. Takeuchi, T. Masaki, D. Chandra, K. Saito, T. Yui and M. Yagi, ChemSusChem, 2017, 10, 687-692.

25 H. Kim, J. Park, I. Park, K. Jin, S. E. Jerng, S. H. Kim, K. T. Nam and K. Kang, Nat. Commun., 2015, 6, 8253.

26 M. Suga, F. Akita, K. Hirata, G. Ueno, H. Murakami, Y. Nakajima, T. Shimizu, K. Yamashita, M. Yamamoto, H. Ago and J. Shen, Nature, 2014, 517, 99-103.

27 J.-R. Shen, Annu. Rev. Plant Biol., 2015, 66, 23-48.

28 I. Zaharieva, D. González-Flores, B. Asfari, C. Pasquini, M. R. Mohammadi, K. Klingan, I. Zizak, S. Loos, P. Chernev and H. Dau, Energy Environ. Sci., 2016, 9, 2433-2443.

29 M. Barra, M. Haumann, P. Loja, R. Krivanek, A. Grundmeier and H. Dau, Biochemistry, 2006, 45, 14523-14532. 
30 A. Riou, Y. Cudennec and Y. Gerault, Acta Crystallogr., Sect. C: Cryst. Struct. Commun., 1989, 45, 1412-1413.

31 M. Wildner, G. Giester, C. L. Lengauer and C. A. McCammon, Eur. J. Mineral., 1996, 8, 187-192.

32 M. Risch, K. Klingan, J. Heidkamp, D. Ehrenberg, P. Chernev, I. Zaharieva and H. Dau, Chem. Commun., 2011, 47, 11912.

33 V. N. Yakovenchuk, G. Y. Ivanyuk, Y. A. Mikhailova and E. A. Selivanova, Can. Miner., 2006, 44, 117-123.

34 D. González-Flores, I. Sánchez, I. Zaharieva, K. Klingan, J. Heidkamp, P. Chernev, P. W. Menezes, M. Driess, H. Dau and M. L. Montero, Angew. Chem., Int. Ed., 2015, 54, 2472-2476.

35 D. Friebel, M. W. Louie, M. Bajdich, K. E. Sanwald, Y. Cai, A. M. Wise, M. J. Cheng, D. Sokaras, T. C. Weng, R. AlonsoMori, R. C. Davis, J. R. Bargar, J. K. Nørskov, A. Nilsson and A. T. Bell, J. Am. Chem. Soc., 2015, 137, 1305-1313.

36 E. R. Losilla, M. A. G. Arandaj, F. J. Ramirez and S. Bruque, J. Phys. Chem., 1995, 99, 12975-12979.

37 M. Risch, F. Ringleb, M. Kohlhoff, P. Bogdanoff, P. Chernev, I. Zaharieva and H. Dau, Energy Environ. Sci., 2015, 8, 661-674.
38 S. Haldar, G. Vijaykumar, L. Carrella, S. Batha, G. T. Musie and M. Bera, ACS Omega, 2017, 2, 1535-1549.

39 C. Pasquini, I. Zaharieva, D. Gonzalez-Flores, P. Chernev, M. R. Mohammadi, L. Guidoni, R. D. L. Smith and H. Dau, J. Am. Chem. Soc., 2019, 141, 2938-2948.

40 M. Jansen, Z. Anorg. Allg. Chem., 1978, 441, 5-12.

41 K. H. Jost, H. Worzala and E. Thilo, Acta Crystallogr., 1966, 21, 808-813.

42 P. D. Blum, A. Durif and J. C. Guitel, Acta Crystallogr., Sect. B: Struct. Crystallogr. Cryst. Chem., 1977, 33, 3222-3224.

43 J. Nguyen-Huy and D. Tahar, Acta Crystallogr., Sect. B: Struct. Crystallogr. Cryst. Chem., 1978, 34, 3727-3729.

44 P. Berthet, J. Berthon and F. d'Yvoire, Phys. B, 1995, 208209, 597-598.

45 G. Caruana, J. Am. Chem. Soc., 1984, 106, 4794-4799.

46 P. A. O'Day, Elements, 2006, 2, 77-83.

47 J. Mähler, I. Persson and R. B. Herbert, Dalton Trans., 2013, 42, 1364-1377.

48 K. Klingan, F. Ringleb, I. Zaharieva, J. Heidkamp, P. Chernev, D. Gonzalez-Flores, M. Risch, A. Fischer and H. Dau, ChemSusChem, 2014, 7, 1301-1310. 